\title{
Reseña de Manual dels hàbitats de Menorca. Hàbitats terrestres
}

\author{
Review of Manual dels hàbitats de Menorca. Hàbitats terrestres
}

\author{
Francesc Xavier Roig-Munar ${ }^{1}$
}
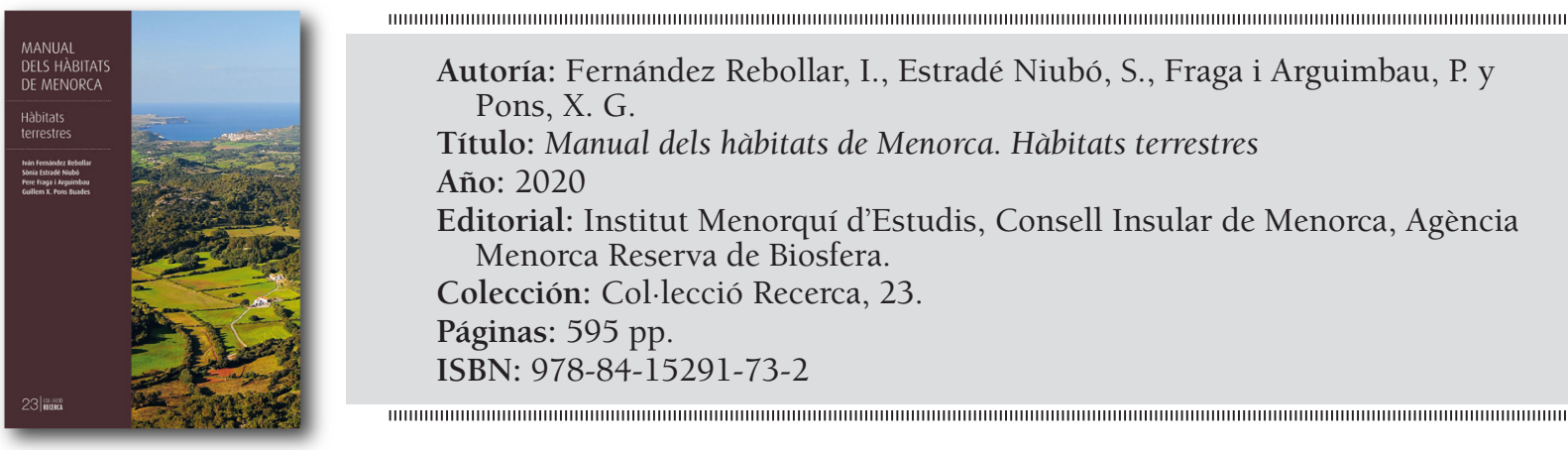

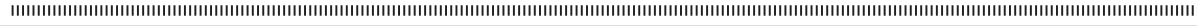

Autoría: Fernández Rebollar, I., Estradé Niubó, S., Fraga i Arguimbau, P. y Pons, X. G.

Título: Manual dels hàbitats de Menorca. Hàbitats terrestres

Año: 2020

Editorial: Institut Menorquí d'Estudis, Consell Insular de Menorca, Agència Menorca Reserva de Biosfera.

Colección: Col-lecció Recerca, 23.

Páginas: 595 pp.

ISBN: 978-84-15291-73-2

Hábitat es el espacio concreto de un conjunto de especies adaptadas a su entorno, y donde el conjunto de hábitats se convierte en un paisaje. Por tanto el hábitat es el resultado de determinadas características geoambientales, tanto físicas como biológicas, que permiten distinguirlos y clasificarlos como espacios resultado de la suma de comunidades de seres vivos y de sus condiciones abióticas. En el caso de Menorca, el conocido como paisaje mosaico, creado en gran parte por la mano del hombre, se encuentra compuesto por diferentes hábitats. Para la ciencia es de vital importancia clasificar los hábitats, a la vez que esta clasificación permite confeccionar un mapa de hábitats, sus interrelaciones y el cálculo de sus superficies, así como la relación con otros espacios, formas y procesos que permiten su planificación y su correcta gestión. La identificación de estos hábitats se asocia generalmente a sus coberturas vegetales, ya que estos suponen un buen indicador de las condiciones geoambientales de los diferentes espacios, a diferentes escalas y a diferentes alturas, ya sea relacionados a condiciones geológicas, geomorfológicas, climáticas y/o antrópicas. Las comunidades vegetales integran los parámetros geoambientales que permiten erigirse como indicadores y darles un valor, siendo su presencia o ausencia una característica de cada hábitat y de cada lugar.

El libro Manual de los hábitats de Menorca ofrece una aproximación precisa a la diversa realidad geoambiental de la isla, mediante la descripción, interpretación e ilustración detallada de sus hábitats, organizados según la adaptación de la codificación internacional CORINE Biotopes Manual. El manual presenta 31 hábitats diferentes, todos ellos terrestres, desde la zona litoral hasta las zonas de tierras agrícolas y antrópicas. Destaca entre todos los hábitats el estuarino, que es una morfología propia de zonas mareales ausente en Baleares.

Metodológicamente la elaboración del manual se ha basado en la descripción y clasificación de los hábitats, donde cada hábitat se ha descrito mediante la nomenclatura y con su relación con otros hábitats. Parte de las descripciones se han basado en la clasificación de las comunidades vegetales, y otros criterios de interacción como la presencia de hábitats mixtos, y la correspondencia con hábitats CORINE. Se realiza una descripción detallada del hábitat y su variabilidad y caracterización ecológica, aportando información de cada hábitat sobre

1 Consultor Ambiental. Dr. en Geografía y Dr. en Geología. C/ Carritxaret, 18 - 6, 07749, es Migjorn Gran, Menorca, España. xiscoroig@ gmail.com 
sus problemas de conservación, planificación, gestión y uso, a la vez que se presentan propuestas de gestión que los autores consideran adecuadas, así como las observaciones más relevantes. Por último de cada hábitat se realiza un exhaustivo listado de la flora característica, y en el caso de las cavidades se realiza un listado de su fauna.

Los tipos de hábitats descritos presentan un grado de detalle elevado, tanto es así que se llegan a describir espacios que hasta el momento eran obviados por investigadores por no adquirir valores ambientales. En este caso se describen ciudades, pueblos y núcleos urbanos (polígonos, entornos urbanos, infraestructuras...), parques urbanos, huertos y jardines..., entre otros. A pesar del nivel de detalle que ofrece, se echan en falta datos relevantes como la geología o la geomorfología aso- ciada a cada hábitat, y que suponen una variable importante para entender el resultado final del mosaico paisajístico de la isla. También se echa en falta un mapa donde se reflejen los hábitats descritos.

El Manual, con muy buena presentación y diseño, se erige como una magnífica herramienta en el ámbito de Menorca, no solo focalizada en la investigación, sino también en la planificación y gestión del territorio, convirtiéndose en el manual de referencia para la futura planificación y gestión territorial. Este manual, editado por la administración pública, actualmente solo se encuentra editado en papel, y su coste puede resultar excesivo como herramienta de gestión con la que tendrían que contar todos los servicios de urbanismo y medio ambiente de las administraciones locales de la isla. 